\title{
The Assimilation of English Transliterations in Chinese
}

\author{
Ding Shi-hua \\ Foreign Language department, Tan kah kee College, Xiamen University \\ Zhangzhou, Fujian Province, China \\ E-mail: 67863238@qq.com
}

\begin{abstract}
Being a type of ideographic language, Chinese characters are known for its close connection between forms and meanings. Proficient Chinese users are subconsciously prone to relate the meaning of a character to its form. This kind of mentality is believed to serve as a bridge between the form and its meaning when it comes to choosing the right characters for those loanwords from English, making them more intelligent to native speakers of Chinese. Those assimilated loanwords greatly enrich Chinese language and promote its expressive ability. This preference of nativization is definitely a tendency of language assimilation in the future.
\end{abstract}

\section{Keywords-Phonemic loans; Transliteration; Nativization}

\section{INTRODUCTION}

Lexical borrowings are a common occurrence in Chinese, which can be traced back to Han Dynasty when different cultures along the Silk Road came into contact. The small number of loanwords in ancient times was mostly confined to the translation of Buddhist Scriptures. The extensive and frequent use of loanwords starts from the implementation of reform and opening-up in the early 1980 s along with the increasing number of international exchange and corporation. As a basic strategy of lexical borrowing, transliteration accounts for the overwhelming majority of Chinese loanwords. A Dictionary of Loan Words and Hybrid Words in Chinese, the most exhaustive of its type in China so far, contains approximately 10,000 phonemic loans from English [1]. These transliterated words are of great help concerning the enrichment of Chinese lexicon, adding a sort of exotic taste to Chinese and promoting its expressive power.

Different from Chinese, English is alphabetic language, which makes it difficult for English transliterations to fit into the Chinese lexical corpus. Nearly all the borrowed words from English have to go through the process of nativization in which adaptations are made so as to conform to the cognitive habit of native Chinese speakers.

In the long history of borrowing words from foreign languages, some managed to be accepted and assimilated into the daily use of Chinese speakers while some died out and were substituted by other alternatives. Then what are the reasons of their assimilation and how should we borrow a new concept from another language? This study is an attempt primarily to explore the features of
English loanwords via transliteration in Chinese and the process of nativization in both phonological and semantic aspects.

\section{SYLLABIC FEATURES OF ENGLISH LOANWORDS}

Lexical borrowing between Chinese and English is an intricate issue. Wallwork claims

"Words are often borrowed from the foreign language but are given the morphological and phonological characteristics of the indigenous language". [2] Belonging to a different language family with English, Chinese has its own distinctive phonological features. Morphologically speaking, in most cases, a Chinese morpheme is consisted of a syllable, which is the basic grammatical and phonetic unit. Syllables are predominantly used as the basic and smallest form of pronunciation in Chinese. Consequently, a phoneme in English will be represented by a syllable in the course of transliteration. On top of that, Chinese and English varies a lot in terms of syllable structures. Chinese has comparatively simple syllabic structure with initials leading the finals, /n/ and /ng/ being the only two consonant endings. In most cases, there is a general rule in Chinese that consonants occur in front of vowels and there are no consonant clusters [3]. Conversely, English has much more intricate structure of syllables. In English, there are no stringent rules regarding the collocation and combination of phonemes. For example, a consonant can be put in front of a vowel or behind a vowel within a syllable, and consonant clusters are not uncommon in English pronunciation. As a result, all of the borrowed words from English have to go through some phonological adaptations so as to conform to the pronunciation rules of Chinese and be assimilated into Chinese lexicon. This is thus the process of nativization. For instance, the English word golf is transliterated as gaoerfu, tank as tanke. The former one is phonetically transliterated as a word with multi-syllables while the latter one a disyllable. This adaptation is the result of careful consideration of the syllabic feature of both the donor language and the recipient language. The voiceless consonants endings $[f]$ in golf and $[k]$ in tank do not comply with Chinese phonetic features, thus, the borrowed words are adapted by a simple addition of final vowels such as $[\mathrm{u}][\mathrm{e}],[\mathrm{i}],,[\mathrm{o}]$ in the process of transliteration. 
Modern Chinese are dominated by words with two syllables, followed by words with three syllables. Four- or more-syllable words are extremely rare in Chinese because more syllables usually means a loose structure within the word. The syllabic feature of modern Chinese imposes a major and tight constraint on the production of transliterated words from foreign languages. Typically, it is highly necessary to take the phonological and cultural traditions of recipient language into consideration in the process of borrowing words from donor languages. Chinese appreciate conciseness and brevity, which contributes to the fact that nearly all transliterated words accepted and preserved in Chinese lexicon are made of two to four characters. Those productions with many characters precisely transliterated phonetically seem unintelligible to native speakers of Chinese and are hardly taken into Chinese lexical corpus. For instance, “international” was originally transliterated as “英特纳雄奈尔”, which has been replaced by “国际”; the purely phonemic transliteration of “modem” (<调制解调器) was replaced by “猫” (<cat) as opposed to the mouse of computer. Similar examples as “逻辑”(logic), 啡”(coffee), 因”(gene), fans)are finally assimilated into Chinese lexicon and widely used by Chinese simply because they are precise phonemic replica of their models and, most important of all, conform to the rules of Chinese word formation and Chinese speakers' cognitive mentality, which requires little effort of interpretation in communication.

\section{AsSociative CONNOTATIONS OF ENGLISH LOANWORDS}

Generally speaking, transliterations should put stress on the phonetic similarity between the loanword and its model word rather than on their associative and evocative effects. However, Chinese phonemic borrowings are taken as an exception. Unlike some orthographic languages, Chinese language is basically ideographic and each character has a meaning or meanings. In Chinese, each morpheme corresponds to a form or a character. It is a unity involving form, sound and meanings. The practice of using Chinese characters to simulate the pronunciation of the model words will inevitably evoke some associative senses. In other words, "characters may build into the meaning of a replica some connotations originally missing in its model. The connotative potential is particularly manifest in the associative meaning of replicas. "Due to the inherent meanings of the characters, some transliterations may arouse positive associations among target language users." [4] For example, the secret state police in Nazi Germany Gestapo is adapted as “盖世太保” , which will be associated with those haughty and defiant bodyguards. Other cases in point are “shampoo” (<香波), which indicates fragrant liquid; “cocacola” (<可口可乐), literally mean delicious and enjoyable; and "Benz" (<奔弛), implying high speed. These transliterations are accepted by Chinese speakers and gradually fit into Chinese lexicon for their good connotations embodied by the Chinese characters.

Chinese is a language rich in homophonous characters, thus the same model may have several distinct variants. It should be noted that it is a common practice in Chinese transliteration of English to link the sense of a replica to its English equivalent by cautiously picking the appropriate one from a heap of homonymous characters. Coiners should always be on alert to choose the ones with proper semantic representations to avert ambiguity or some negative associations. Chinese have long been known for their tradition of rectification of names, who will ponder on the choices of characters deliberately in translating name of a person or a place, straining to "bring into full play the expressive power of those characters." [4] Classic and qualified phonemic loans help to produce true and intelligible associations which require little efforts of interpretation from the recipient language users. For example, the literal meaning of "vitamin "is stuff of vital importance. Its phonetic adaptation in Chinese is“维他命”or “维生素”, indicating being related and critical to life, which has great phonetic resemblance with the model and suggests some appreciative connotations. For another example, "coolie" literally means manual labors who are working really hard in unfavorable conditions. Its transliteration of “苦力” (< hardworking laborers) is extremely felicitous phonetically and semantically. Likewise, In the case of "Rose", the variants “路斯” or “录思”, indicating “road \& this” and "tape \& reflection" respectively, are rarely taken as names for a girl, while the homonym “露丝” ( $<$ dew and silk) suggesting someone who is gentle and feminine often finds its way into girls' names [5].

These semantic meaning related transliterations differ from each other in regard to their distinctive features.

\section{A. Application of semantic radicals}

The small number of syllables in Chinese phonological system leads to the existence of large amount of homonyms and morphemes with similar sounds. There are no established rules governing the selection process. Therefore, a transliterated loanword would have a couple of variants when it is initially borrowed from a foreign language. Take "sauna" as an example, it used to be transliterated as “桑 那, 桑娜” and “桑拿” . Some Chinese morphemes are composed of phonetic indicators and image radicals, suggesting the sound and semantic category of the characters. In the course of regulation and unification of foreign borrowed words, loans with unified forms and meanings eventually beat other variants and are accepted as the theoretical basis for word-building. "Sauna" is universally transliterated as “桑拿”, because the morpheme “拿” often reminds people of the traditional Chinese way of health care---推拿 (<Chinese massage). Relevant radicals are therefore often employed for the purpose of adding some semantic values to the phonemic loans, which can be manifested in the transliteration of plant names: the radicals 木 and $\#$ are used, as in 柠檬 $(<$ lemon), 槟榔 (<areca nut), 柿苓 (<stillingia) and 莞 冦 (<cocoa). As the radicals are ideographic, they are suggestive of one semantic component of the replicas. Similarly, replicas with the radical $\square$ indicate that they designate something edible or drinkable, as in 咖啡 (<coffee) and 咖啀 (<curry) [6]. 
Chinese people tend to reject meaningless phonemic borrowings, many of which have been replaced by alternatives with meanings. Sometimes, a Chinese morpheme indicating the category of the object is added to the phonemic transliterations, which does not exist in its original model word. This effort is effective in crystallizing the meaning of the model word. For example, “violin” used to be represented as “梵婀玲”, which has some phonemic similarity with the model word but fail to make senses to Chinese speakers. The current adaptation as “小 提琴” makes it possible for us to relate the referent to the form. For another example, the combination of “艾滋” (<AIDs) makes no sense for Chinese users based on their individual semantic meanings. A category note 病 $(<$ disease)putting at the end of it (艾滋病) help to mark the semantic category of the replica, making it clear to recipient language users that it is a kind of disease rather than something else. Similar examples are "bear" (啤酒), “sauna”(桑拿浴), “sardine”(沙丁鱼), “mohair”(马海毛), “Jeep”(吉普车), “dink”(丁克家庭), “Tittup”(踢踏舞), “bar”(酒 吧) and so on.

To sum up, a single radical or morpheme note is essential as to the indication of semantic category of replica. People can have some clue of the semantic meaning of the replica based on these elements. So it is fair to say that "ingenious use of these radicals may give full play to their ideographic value and increase the intelligibility of transliterations." [4]

\section{B. "Demorphemication" of some transliterations}

Most Chinese characters are literally special morphemes containing both meanings and sounds. When a Chinese character is employed as a syllabic notation to represent the pronunciation of a foreign word, the replica not only has phonetic resemblance with the model, but also evokes some associations among the recipient language users because of its property as a minimum carrier of semantic meaning in Chinese. That is to say, it is a common occurrence in Chinese that the phonetic representation of a borrowed word goes with certain semantic implications.

However, despite the function of producing phonetic resemblance and semantic association, certain characters tend to be "demorphemized" when the combination of them in a transliteration makes no sense to native Chinese speakers. In other words, instead of being a semantic indicator, the characters will literally serve as a syllabic notation [7]. For example, in words like “坦克 (tank), 沙发 (sofa), 咖啡 (coffee), 克隆 (clone), 巧克力 (chocolate), 奥林匹克 (Olympic)”, the combination of the characters is intelligible to Chinese speakers with no further information of the referent. The characters involved therefore are only used to simulate the sound of the original. In some cases, in order not to connect the referent to something evil, making the original meaning derogatory and undesirable, it is preferable to choose words whose combination is not indicative of anything. For instance, “萨斯”would be better than “杀死” $(<$ SARS) and “艾滋病” would be better than “爱之病”. After all, AIDs is not a disease developed from love or love-making.

\section{Homophonic Phonemic Loans}

Transliterations embody semantic connection of some sort to their models. For example, loanwords such as “可口 可乐 and “奔驰” have received great publicity due to their good associations, we have to be aware that the implied meanings do not correspond to the semantic connotations of the models, which therefore can't produce the same cognitive effects as they do to the source language speakers. In the above example, 可口 means 'tasty' and 可乐 'amusing and delightful', while Coca Cola is in fact a carbonated soft drink with extracts of kola nuts and coca leaves. As for “奔驰” ( $<$ Benz), it is not a brand name indicating fast speed in English but the name of the creator of the company, Karl Friedrich Benz. In the word 蹦极, we use the elements 蹦 ('jump') and 极 ('extreme') to simulate the pronunciation of the English word 'bungee', which implies that bungee jumping is the sport of 'jumping to the extreme'. However, based on etymology, bungee refers to the stretchable cord that pulls the jumper back before he or she hits the ground or water.

As can be shown from the above examples, it often occurs that those positive literal meaning or association evoked by the character or combination of characters is not relevant to the real semantic connotation of the model word in the source language. These transliterations can be taken as the products of "reanalysis". [8] Shi renamed it ('homophonic phonemic loan'), since such words have little to do semantically with the original and are not done exactly phonemically [6].

To summarize, loanwords borrowed via representing the sounds of the original can't be categorized as ones with phonemic and semantic accuracy. They are, in large part, pure transliterations, which are defined as 'homophonic phonemic loans' according to Yang Xipeng. [3]

Besides the theoretical principles in word-building, there are some loans which finally fit into the Chinese society because of either the authoritative rectification or natural evolvement through lots of social practice.

\section{CONCLUSION}

In a word, Chinese transliteration of English must be conducted in compliance with the cognitive mentality of Chinese people and inherent syllabic rules of Chinese language. This is the process of assimilation or nativization. Reasons attributing to this adaptation are complicated and the interplay between these elements lead to the production of those loanwords which eventually find their way into the Chinese lexicon. If a word want to be "borrowed from one language into another, and become lexicalized, i.e., assimilated phonetically, graphemically, and grammatically, into the new language," [9], a coiner should not only give primary concern to the phonetic resemblance between the recipient language system and the donor language system, it is also essential for those converted words to conform to the syllabic features of Chinese language and cognitive conventions for native Chinese speakers. 
Localized transliterations in Chinese have become an integral part of Chinese lexicon after long time of adaptation, which greatly enrich Chinese vocabulary and promote the expressive power of Chinese.

\section{REFERENCES}

[1] Liu, Z., Gao, M., Mai, Y., \& Shi, Y. A dictionary of loan words and hybrid words in Chinese. Shanghai: Shanghai Lexicographical Publishing House. 1984.

[2] Wallwork, J.F. Language and Linguistics. London: Heinemann Educational Books. 1980.

[3] Yang Xipeng. Chinese Morpheme. Nanjing: Publishing House of Nanjing University, 2003.
[4] Yan Chen. On Lexical Borrowing from English into Chinese via Transliteration [J]. English Language and Literature Studies, Canadian Center of Science and Education.2013 (3).

[5] Zhan Bei. Name Translation and Culture [J]. Chinese Translators Journal, 2001 (1)

[6] Shi, Y. 2000. Loan Words in Chinese. Beijing: Commercial Press Ltd.

[7] Feng Jianwen.et al. The Translating Approach of Loanwords [J] Social Sciences Riview, 1998 (4).

[8] Zhou, C., Jiang Y., Wailaici and English borrowings in Chinese. English Today, 2004 (7).

[9] Bussmann, H. Routledge dictionary of language and linguistics. London: Routledge. 2004. 